\title{
EFFECT OF THERMAL AGING ON MECHANICAL PROPERTIES
}

\section{AND FATIGUE BEHAVIOR OF PP/HDPE THERMOPLASTIC}

POLYMER NANOCLAY COMPOSITES

\author{
PYDI HARIPRASADARAO ${ }^{1}$, H. RAVISANKAR ${ }^{2} \&$ V. CHITTARANJAN DAS ${ }^{3}$ \\ ${ }^{1}$ Research Scholar, Acharya Nagarjuna University, Guntur, India \\ ${ }^{2}$ Gandhi Institute of Technology and Management deemed to be University, Visakhapatnam, Andhra Pradesh, India \\ ${ }^{3} R V R \&$ JC College of Engineering, Guntur, Andhra Pradesh, India
}

\begin{abstract}
Thermoplastic polymers are gaining their importance in their usage and emerging into industrial applications. Material degradation and loss of its properties due to exposure to different environmental conditions restrict their usage in engineering applications. The inclusion of nanofillers in these polymers can enable their usage in engineering application by reducing the degradation of the material. In the present study two thermoplastic polymers, Polypropylene (PP) and High-Density Polyethylene (HDPE) are considered for fabrication of nanoclay included thermoplastic polymer clay nanocomposites by melt blend method. These composites are exposed to the higher temperature to study the effect of thermal aging on mechanical and fatigue properties of nanoclay included PP/HDPE thermoplastic polymer nanocomposites. Nanoclay inclusion reduces the decrease in these properties due to thermal aging.

KEYWORDS: Thermal Aging, Polypropylene, High Density Polyethylene \& Degradation
\end{abstract}

Received: Aug 26, 2018; Accepted: Sep 16, 2018; Published: Nov 02, 2018; Paper Id.: IJMPERDDEC201839

\section{INTRODUCTION}

Thermoplastic polymers are gaining their importance in their usage and replacing conventional metals in modern industrial applications. Introduction of nanoparticles into thermoplastic polymers for fabrication of nanocomposites has attracted attention due to their effective enhancing of physical, chemical, mechanical properties, thermal stability and flame retarding tendency compared to micronized fillers [1-2]. The inclusion of Nano $\mathrm{Mg}(\mathrm{OH})_{2}$ significantly enhances tensile strength, a hardness of polypropylene (PP) nanocomposites [3]. Grafted $\mathrm{SiO}_{2}$ nano particles in High-Density Polyethylene (HDPE) matrix considerably improve Tensile strength, Tensile Stiffness, Impact properties of HDPE nanocomposites [4]. Addition of $\mathrm{Sio}_{2}$ nanoparticles in PP influences tensile strength, tensile toughness and impact strength of $\mathrm{PP} / \mathrm{SiO}_{2}$ nanocomposites [5]. Thermal and thermooxidative degradation conditions shift the characteristic temperature to lower values when exposed to different temperatures at different time periods [6]. Thermal cracking of HDPE has been investigated in the presence of solvents with different hydrogen-donating capabilities by D. P. Serrano et al [7], The presence of wood powder in PP/HDPE, and MAPP/HDPE thermoplastic polymers increases the thermal stability and stiffness of the composites but adversely tensile strength decrease with wood powder content [8]. HDPE composites with a different weight fraction of silver nanoparticles were fabricated to study the influence of silver nanoparticles on thermal stability and tensile properties when exposed to UV radiation. A significant influence of these nanoparticles on thermal 
degradation and tensile strength were reported [9]. Maleate HDPE (MHDPE) composites, with the inclusion of unmodified $\left(\mathrm{SiO}_{2}\right)$ or modified spherical $\mathrm{Sio}_{2}$ containing immobilized silver/Copper $\left(\mathrm{Ag}-\mathrm{SiO}_{2}\right) /\left(\mathrm{Cu}-\mathrm{SiO}_{2}\right)$ nanoparticles with enhancing interaction between silica and polymer matrix, were fabricated, Nanosilica significantly improves thermal stability of HDPE thermoplastics for thermo-oxidative degradation [10]. Addition of fumed $\mathrm{Sio}_{2}$ to $\mathrm{HDPE}$ thermoplastic enhances the stiffness of the composite monotonically with silica loading whereas tensile strength increases up to an extent and then decrease. An adverse effect of $\mathrm{Sio}_{2}$ on impact strength was observed however the thermal stability of the composite increases with silica loading [11]. Presence of $\mathrm{C}_{60}$ in HDPE enhances the thermal stability properties in the air and reduces the tendency of flammability [12]. Addition of fillers in polymeric composites has a considerable impact on the oxidative thermal degradation due to excessive polar groups $(-\mathrm{OH})$ supplied by the fillers. Nonmetallic fillers obtained from waste electronic printed circuit boards were reinforced to enhance tensile and flexural properties of HDPE polymer composites [13]. Significant improvement in mechanical and flexural properties was reported by Shuangqiao Yang et al. The degradation properties of wood reinforced HDPE composites when exposed to temperatures, rain, UV rays for long period were elaborately presented by Rongzhi and $\mathrm{Li}$ [14]. The micro-hardness, thermal stability, flammability and calorimetric characteristics of different functionalized polyethylene Clay Composites were studied by Minkova et al. Considerable effect of clay on the above properties of polyethylene was reported [15]. Thermal degradation of polypropylene due to high-temperature aging weakened the polymer and is highly depends on the time for which it is exposed. Thermal aging is more predominant when the material is exposed to artificial heating rather natural environmental heating [16]. Influence of nanoclay on the kinetics of polypropylene at moderated temperatures was modeled and validated experimentally [17]. The molecular dynamics simulations [18] reported a reduction in Young's modulus and shear modulus due to the thermal aging of polyurethane. Thermal stability of polypropylene nanocomposites with bentonite was explored by Florencio et al [19].

Many works reported on the thermal aging behavior of thermoplastic polymers are confined to degradation mechanisms and their effect on mechanical properties. Works reported the influence of thermal aging on fatigue behavior of thermoplastic polymer nanocomposites and the effect of nanofiller inclusions on fatigue properties due to thermal aging is seldom found.

In the present work influence of thermal aging on fatigue life of thermoplastic polymer nanocomposites with nano clay inclusions are studied. Two polymers Polypropylene (PP) and High-density polyethylene (HDPE) are considered to study the thermal aging effect on fatigue behavior of these polymers and the influence of nanoclay additions and its weight fractions on fatigue life and mechanical properties of these nanocomposites.

\section{MATERIALS AND METHODS}

Polypropylene (PP) and High-density polyethylene (HDPE) supplied by Allied agencies, Hyderabad, India, and Nanoclay obtained from Nanoshell, Mumbai, India.

\subsection{Sample Fabrication}

Tensile samples of thermoplastic materials are fabricated by melt compounding method by a twin screw extruder and injection molding. All the thermoplastic polymers in the present work were dried in a vacuum oven for 12 hours at $60^{\circ} \mathrm{C}$ for removal of moisture in the thermoplastic polymers. Polypropylene (PP) and High-density polyethylene (HDPE) granules with different nanoclay weight fractions $(0.5 \%, 1 \%, 3 \%$, and $5 \%)$ were pre-mixed thoroughly in a high-speed mechanical mixer. A small quantity of paraffin ( $3 \%$ weight of nanocaly) was added to the mixture before it is fed to the 
twin screw extruder. Temperatures of $200^{\circ} \mathrm{C}, 210^{\circ} \mathrm{C}$ were set along the barrel for PP, HDPE polymers respectively during fabrication of the samples and the screw speed was set to $100 \mathrm{rpm}$. The cylindrical wires are drawn from the twin screw extruder pass through the water bath for subsequent cooling. These wires were cut into pallets to feed into injection moulding. The pallets were preheated for 12 hours in the oven at $80^{\circ} \mathrm{C}$ for removing of moisture gain during cooling in the water bath. Dumbbell-shaped tensile specimens $(105 \times 10 \times 4 \mathrm{~mm})$ as per ASTM -D638 were injection molded using vertical spindle type injection molding machine. Molding pressure of $150 \mathrm{Mpa}$ at the pre-specified temperature and a fill time of 10 sec and cooling time of $20 \mathrm{sec}$ were set during molding.

\subsection{Thermal Aging}

All varieties of the samples are exposed to a constant temperature of $100^{\circ} \mathrm{C}$ for 24 hours in a hot air oven to study their tensile and fatigue behavior after thermal aging. After $24 \mathrm{hrs}$ specimens were removed from the oven and cooled to room temperature for further studies.

\subsection{Morphology}

It is evident that the level of dispersion of nanofillers in the matrix greatly affects the properties of the nanocomposites. Tensile fracture surfaces were used for scanning electron microscope (SEM) specimens to study the dispersion level of nanoclay in the polymer matrix. Zeiss EVO MA15 SEM with an acceleration voltage of 10kv was used for morphology studies. As the considered polymers are not conductive, samples were sputter coated with gold before they exposed to SEM.

\subsection{Tensile Testing}

Tensile specimens before and after exposure to thermal aging were tested using Instron 8801 ASTM: D638 standards were adopted and a cross-head speed was set to $1 \mathrm{~mm} / \mathrm{min}$ during the test.

\subsection{Fatigue Testing}

Fatigue test was conducted on fresh [20] and thermal aged tensile specimens using Instron 8801 fatigue testing machine. All tests carried out under the Tensile-Tensile mode to avoid additional fixtures for preventing from buckling in case of Tensile- compression mode. A stress ration $\mathrm{R}=\frac{\text { Minimumstress }}{\text { MaximumStress }}, \mathbf{R}=\mathbf{0 . 1}$ and an amplitude ratio $\boldsymbol{a}=\frac{\text { AmplitudeStress }}{\text { MeanStress }}=\mathbf{0 . 8}$ were set during the test. Initially, maximum amplitude was chosen as 0.7 times of the ultimate tensile strength and the number of cycles before the fatigue damage was recorded. Gradually the amplitude stress $(0.6,0.5$, 0.4 times of their respective ultimate tensile strength) varied and corresponding fatigue life was recorded. A frequency of $10 \mathrm{~Hz}$ is set for the specimen during the test.

\section{RESULTS AND DISCUSSIONS}

\subsection{Morphology}

Tensile fracture surfaces of the thermoplastic polymer were examined by scanning electron microscopy (SEM) to study of dispersion level of nanoclay in the polymer matrix. Figure 1 to Figure 4 presents some significant SEM images of HDPE and PP nanocomposites before aging and after aging. It is evident that the fabrication procedure is able to get a good dispersion. No significant agglomerations were observed in any of the cases. Thermal aging for 24 hours at $100^{\circ} \mathrm{C}$ has no significant effect on morphology. After thermal aging, it can be noticed that in some portions the fading of color may be 
indicating the initiation of degradation of the polymer but it is not evident an abnormal distortion of nanoclay particles.
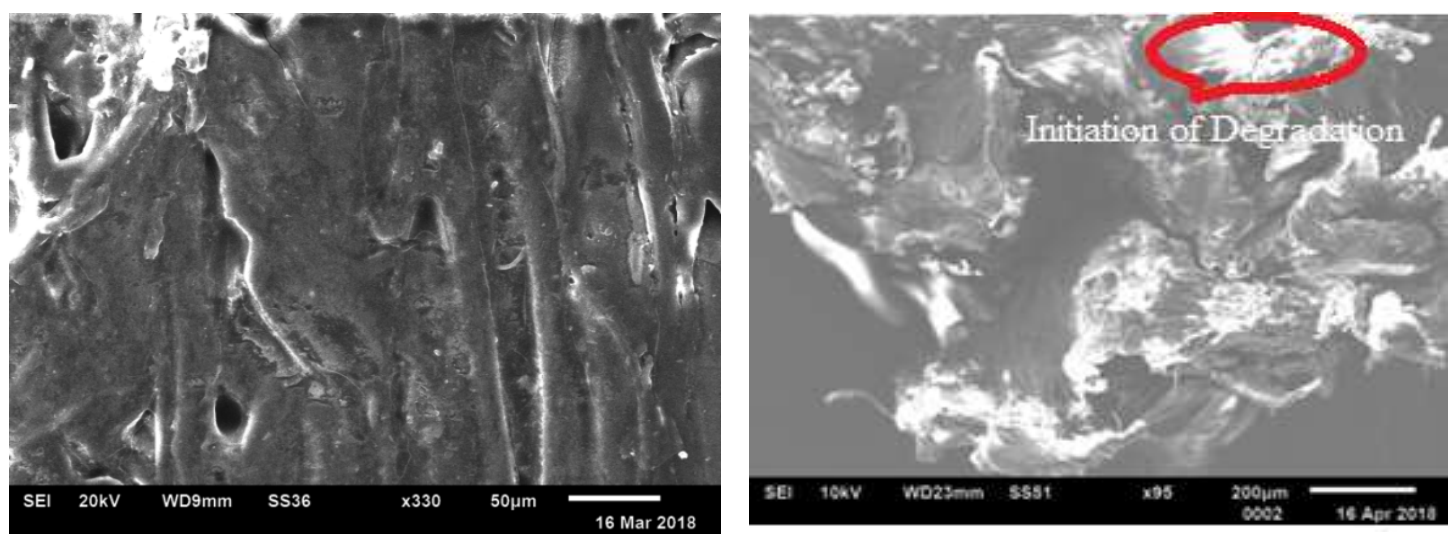

Figure 1: Neat Polypropylene Before and After Thermal Aging
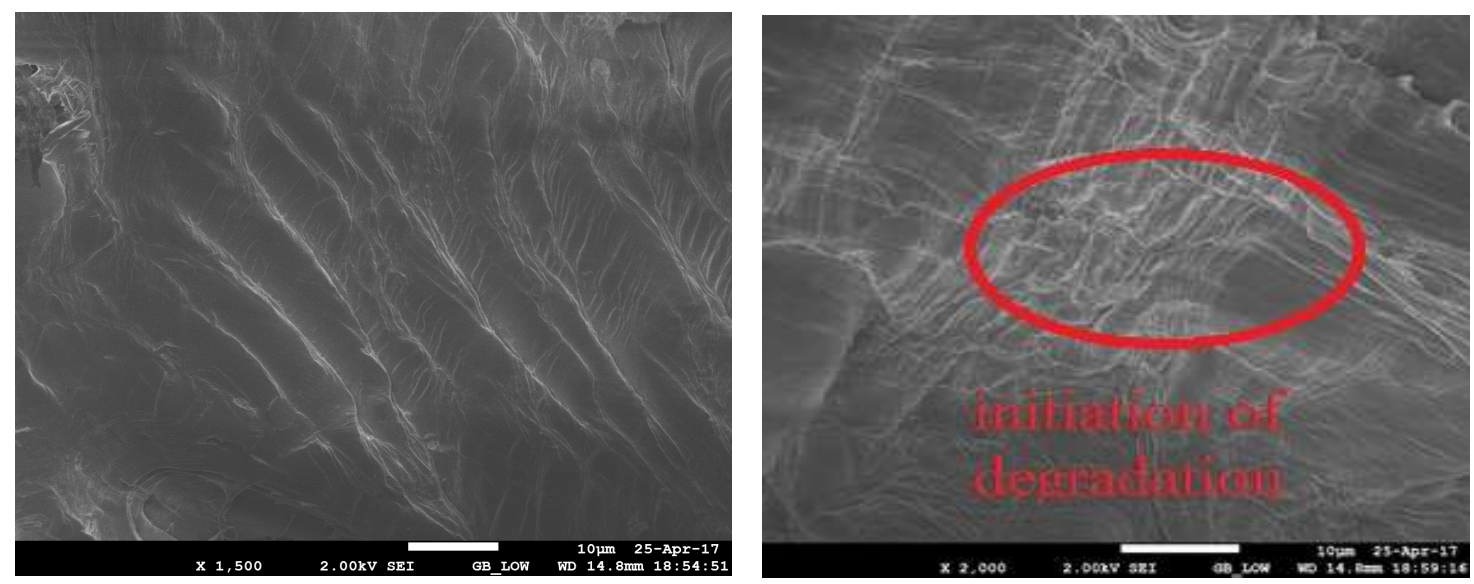

Figure 2: High Density Polyethylene Before and After Thermal Aging
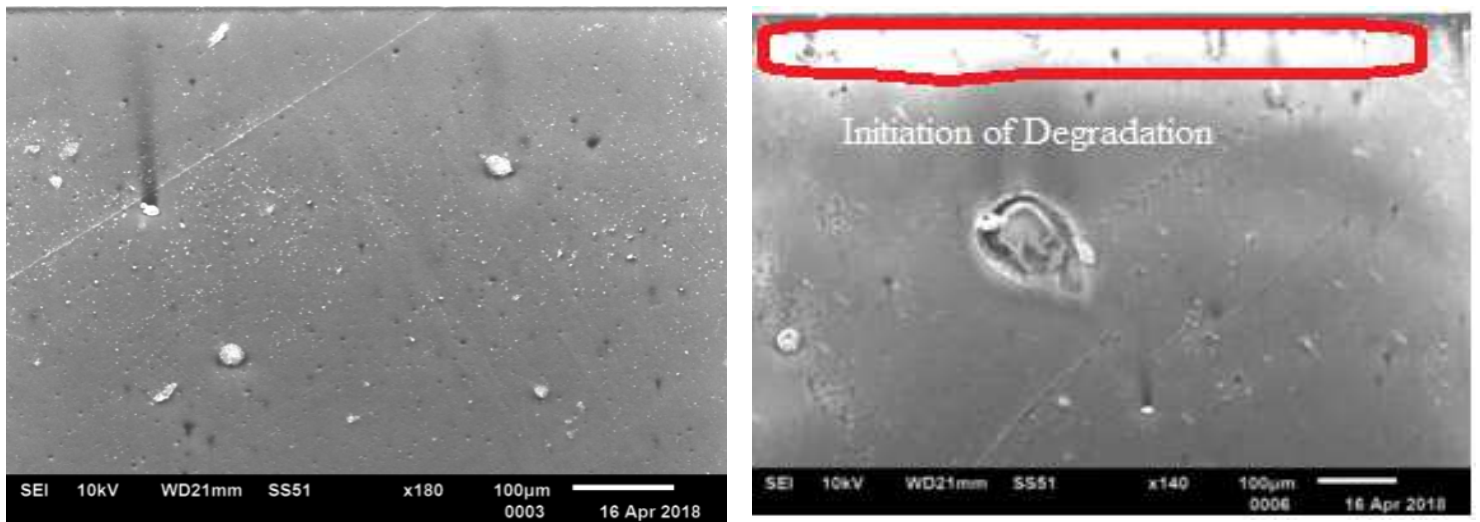

Figure 3: Polypropylene and After Aging at $0.5 \%$ of Inclusions of Nano Clay 

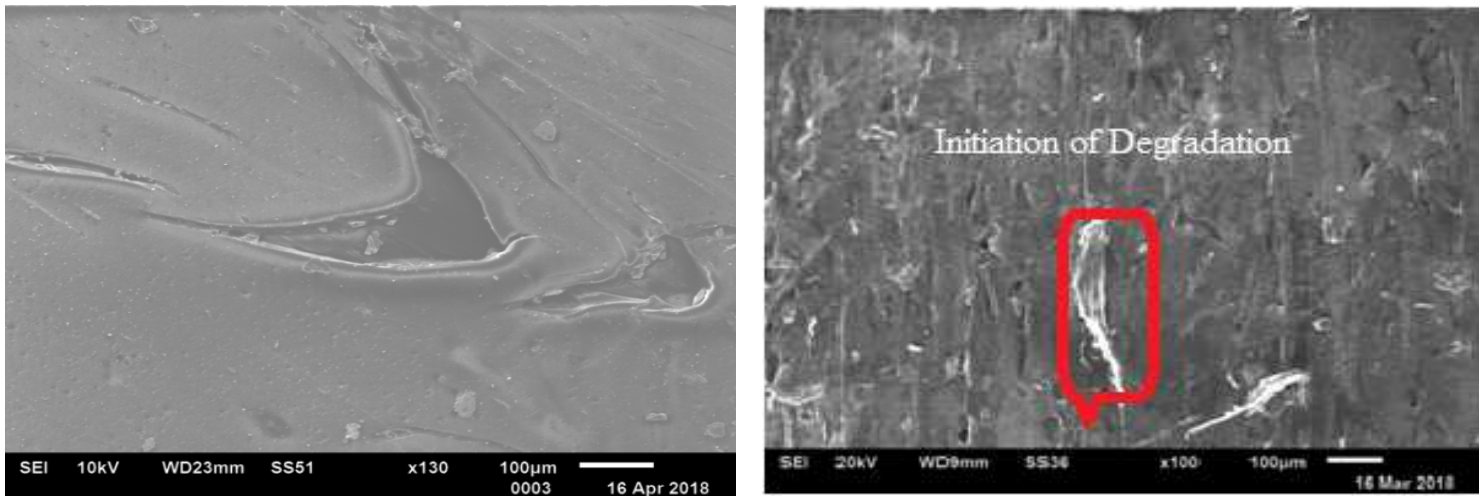

Figure 4: HDPE at 1\% Nanoclay Inclusion Before and After Thermal Aging

\subsection{Tensile Properties}

Stress-strain curves obtained during the test on thermal aged and unaged specimens of all the thermoplastic polymers considered are reported in Figure 5 to Figure 6. The extract of the curves is subsequently reported in Figure 7 to Figure 8. It can be inferred that the addition of nanocaly in polymer enhances its tensile properties. Tensile strength at $5 \%$ nano clay loading increase around 22\%, 20\% for PP, HDPE respectively. A similar trend was observed in the case of stiffness. An increase of $11 \%, 15 \%$ was reported at 5\% loading of nano-clay for PP, HDPE thermoplastic polymers. It is well known that the stress transfer between matrix and nanoparticles through interfaces. At the higher loading of nanoclay lager surface area available for stress transfer and a load are distributed may be the reason for reporting high strength and stiffness. In addition, the nanoclay particles restrict movement of polymer chains may be also a reason for the enhancement of these properties. It is evident that thermal aging increases the percentage of elongation at the break and decrease tensile strength and tensile modulus for virgin thermoplastics. The reduction in tensile strength is $21 \%$, 25\%, and Young's modulus is around $12.31 \%$, $14 \%$ for PP, HDPE respectively. Similarly, the reduction of these properties at 5\% loading of nano clay is $8 \%, 9 \%$, in case of tensile strength and $4.1 \%, 5.4 \%$ in case of Young's modulus for PP, HDPE respectively. It is evident that the reduction in tensile strength is significant for virgin polymers. However, the reducing tendency of tensile strength due to degradation of the polymer decreases with nanoclay weight fraction. This may be attributed due to the fact that the aging temperatures will not affect nanoclay. Results reveal that thermal aging has no significant effect on tensile modulus.
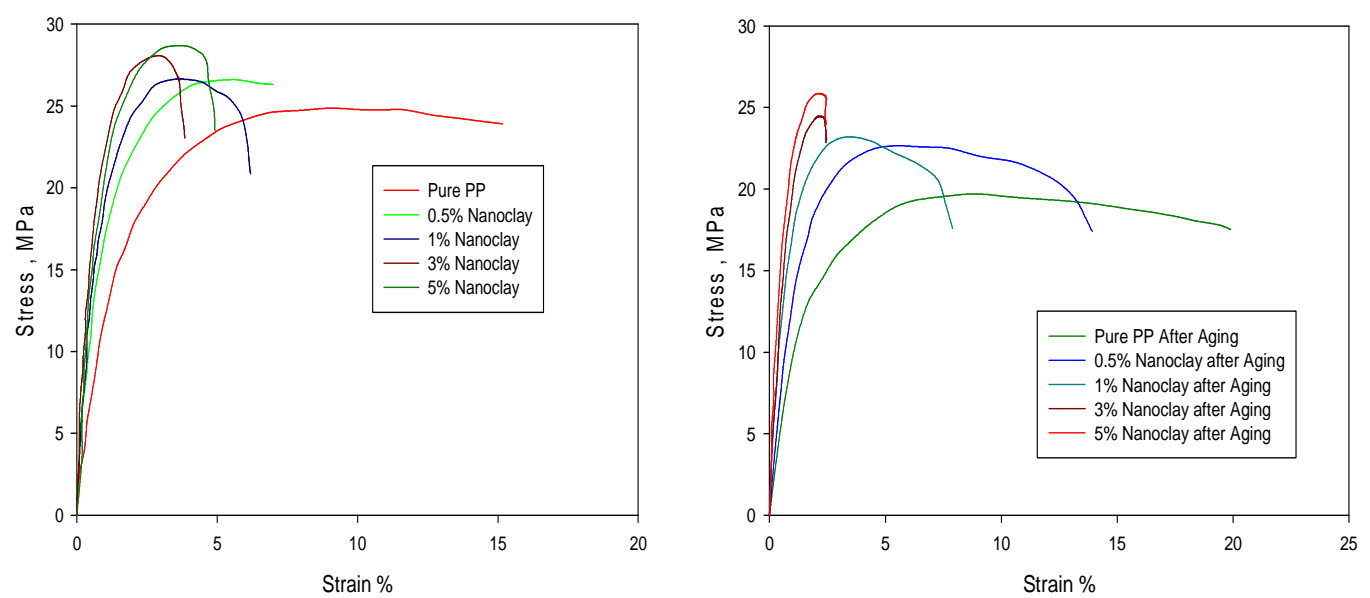

Figure 5: Stress-Strain response of Polypropylene Nanoclay

Composites Before and After Thermal Aging 

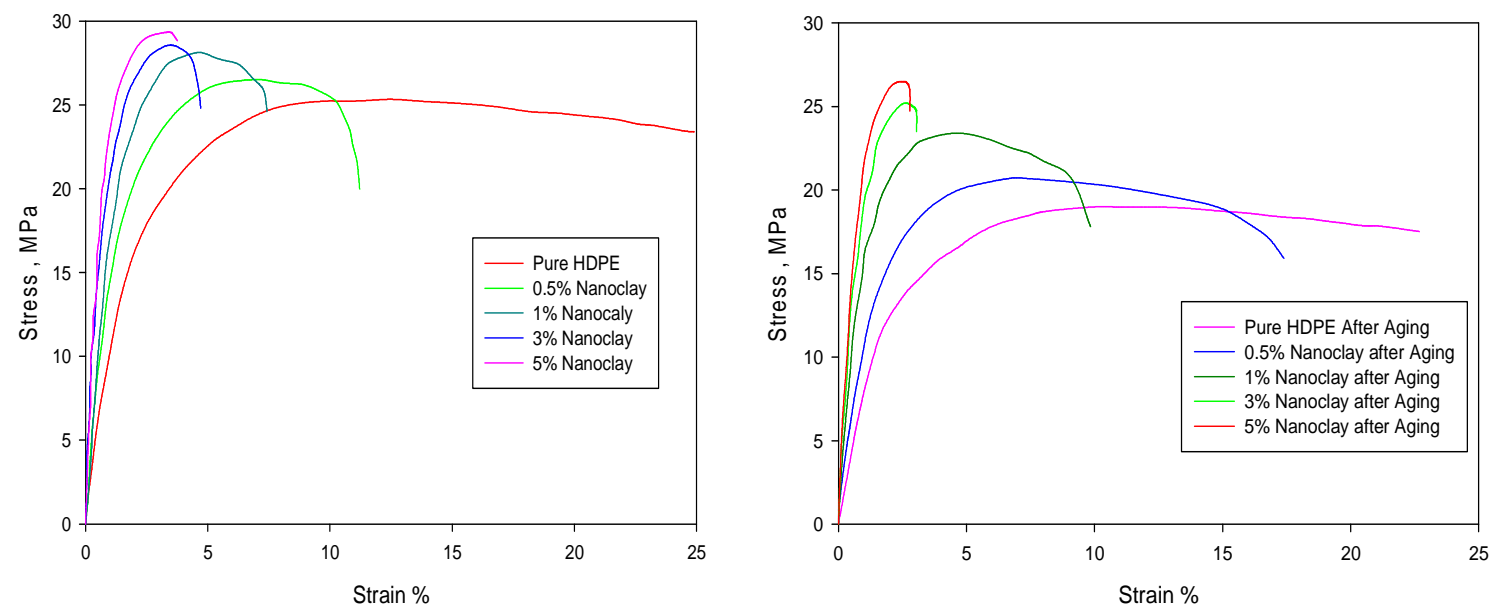

Figure 6: Stress-Strain Response of HDPE Nanoclay Composites Before and After Thermal Aging
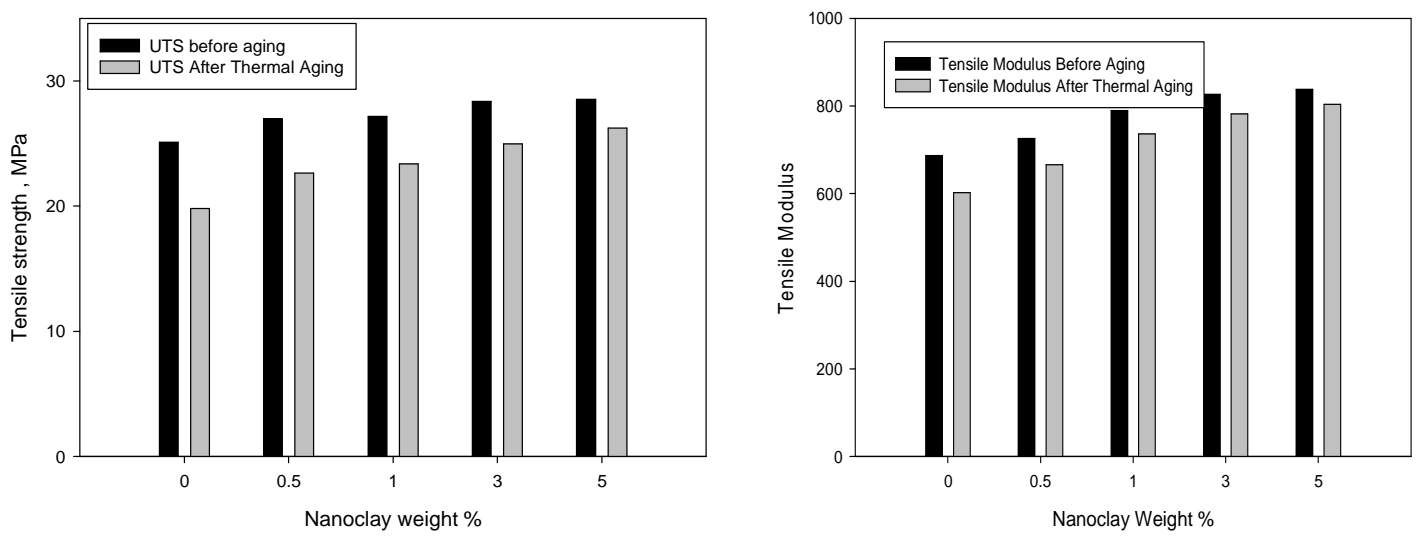

Figure 7: Tensile Strength and Tensile Modulus f Polypropylene Nanoclay Composites
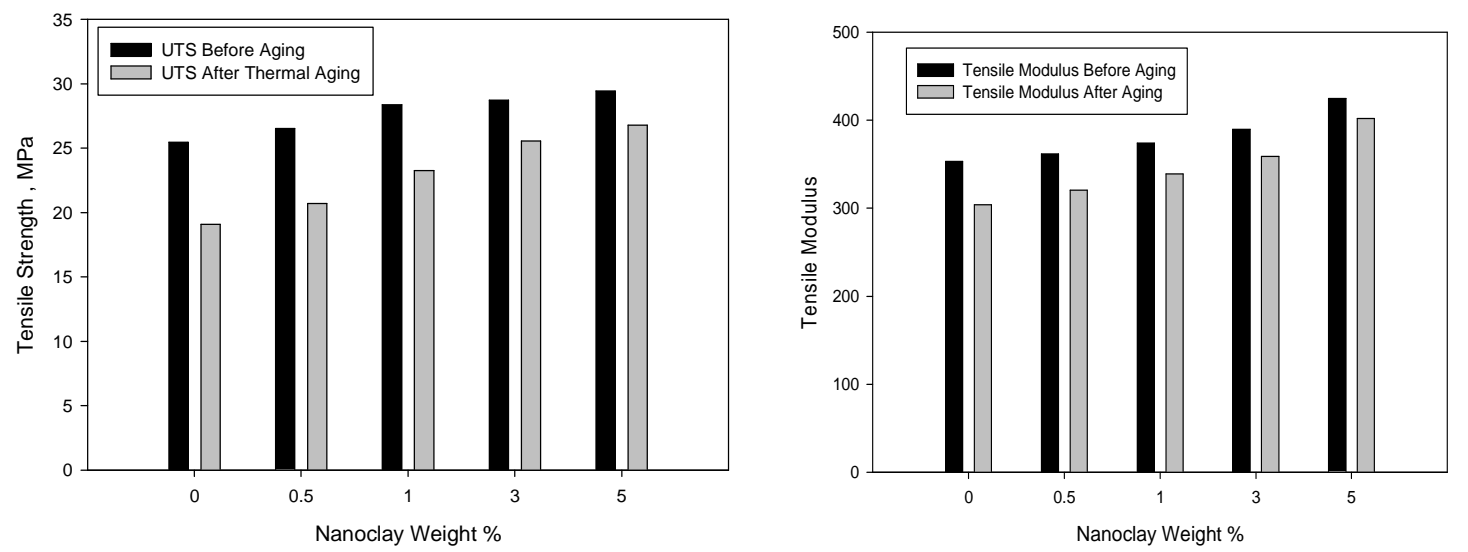

Figure 8: Tensile Strength and Tensile Modulus of High Density Polyethylene Nanoclay Composites

\subsection{Fatigue Behavior}

Fatigue behavior before and after thermal aging of thermoplastic polymer nanocomposites are reported in Figure 9 to 10. It is evident that the inclusions of nanoclay particles enhance the fatigue life of the composites. Results reveal that thermal aging decreases the fatigue life of the composites. For virgin polymers, the decrease in life is around $35 \%$, $33 \%$ for 
PP, HDPE respectively. Whereas at 5\% loading of nanoclay inclusion the decrement in fatigue life due to thermal aging is found to be $20 \%, 11 \%$ for PP, HDPE respectively. From the results reported it can be concluded that nanoclay additions reduce the decrement in the fatigue life due to thermal aging. However, the fatigue life of aged nanocomposites increases with nanoclay weight fractions. Fatigue life of aged nanocomposites at 5\% nanoclay loading subjected a maximum stress of 0.7 times its ultimate tensile stress increases by around 72\%, 87\% for PP, HDPE polymers. It is observed (Figure 9 to 10) that for same stress level the fatigue life of nanocomposites enhances with a weight fraction of nanoclay. This reduction in a decrement of fatigue life of nanocaly included thermoplastic composites may be due to higher thermal stability of nanoclay when compared to thermoplastics.
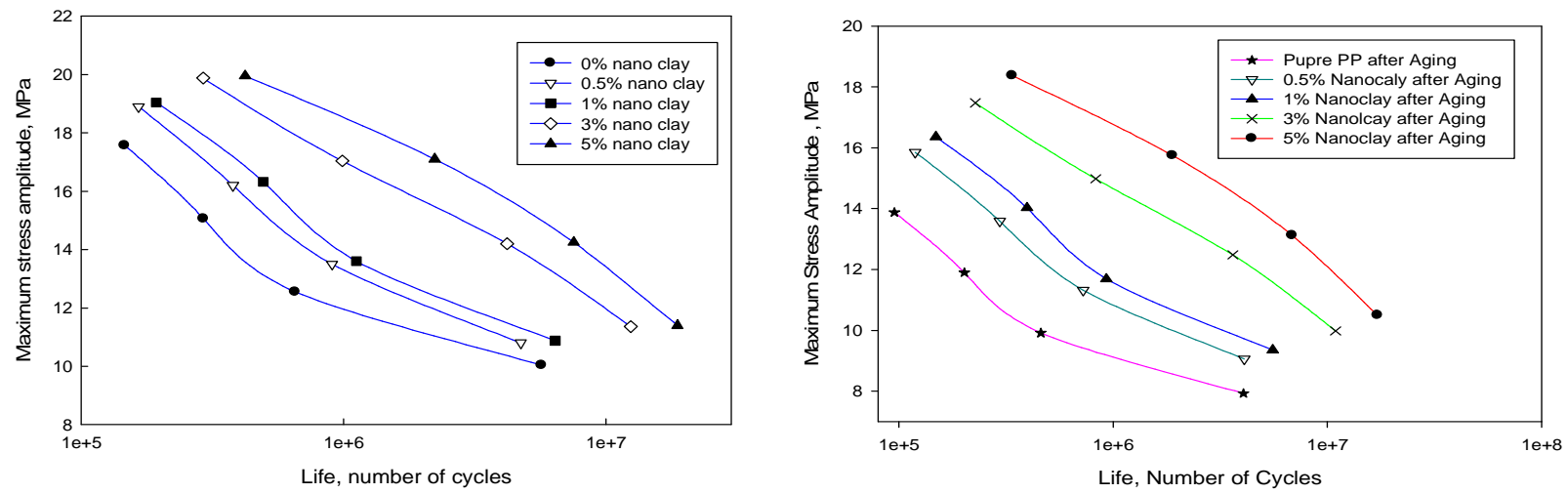

Figure 9: S-N Curves for Polypropylene Nanoclay Composites Before and After Thermal Aging
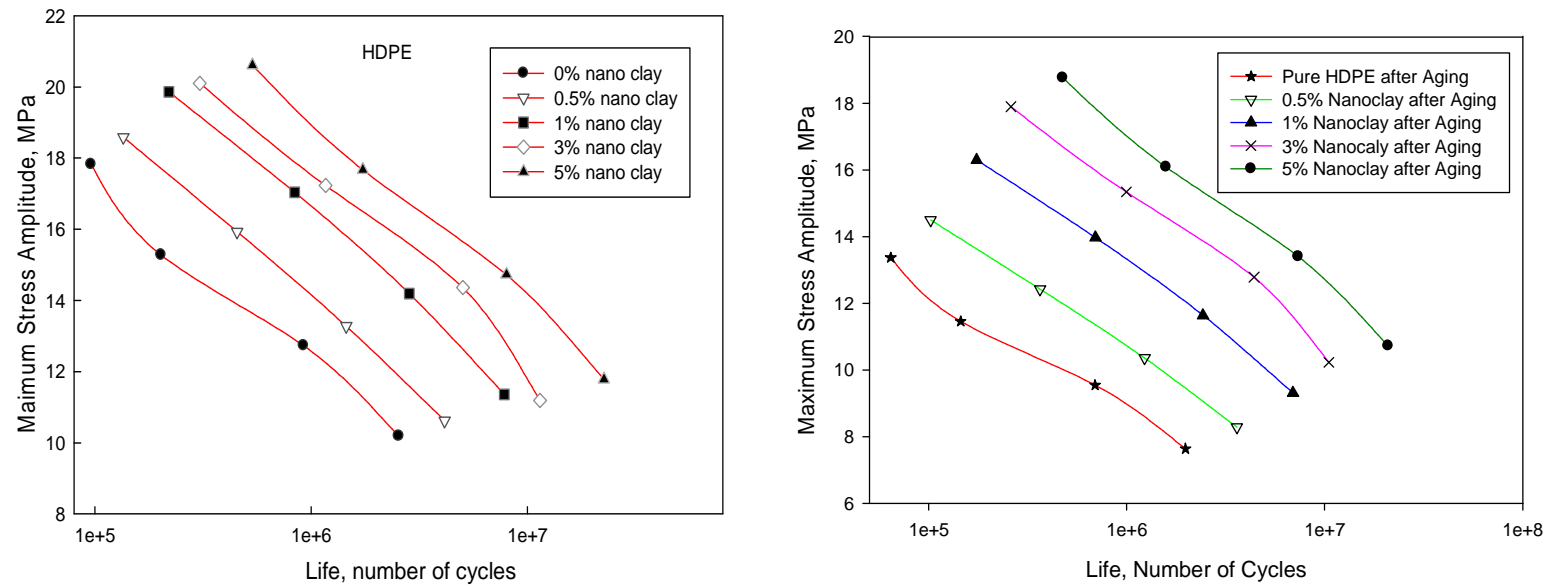

Figure 10: S-N curves for HDPE Nanoclay Composites Before and After Thermal Aging

\section{CONCLUSIONS}

In the present study PP, HDPE thermoplastic polymer nanocomposites with nanoclay inclusions were fabricated by melt blend method and exposed to the higher temperature to study thermal aging behavior. Tensile and fatigue properties were conducted on aged and unaged specimens. Thermal aging has a significant influence on tensile strength and fatigue properties of nanocomposites. An addition of nanoclay enhances its tensile and fatigue properties of nanocomposites and reduces the damage due to thermal aging. 


\section{REFERENCES}

1. C.Saujanya, S.Radhakrishnan, (2001).Structure development and crystallization behavior of PP/nanoparticulate composites, Polymer 42, 6723-6731.

2. Michael Alexandre, Philippe Dubois, (2000). Polymer-layered silicate nanocomposites: preparation, properties and uses of a new class of materials, Materials Science and Engineering, 28, 1-63.

3. S. Mishra,S. H. Sonawane, R. P. Singh, A. Bendale, K. Patil, (2004). Effect of Nano-Mg(OH)2 on the Mechanical and FlameRetarding Properties of Polypropylene Composites, Wiley Interscience, DOI 10.1002/app.20750.

4. Ming Qiu Zhang, Min Zhi Rong, Hai Bo Zhang, Klaus Fried Rich, (2003). Mechanical Properties of Low Nano-Silica Filled High Density Polyethylene Composites, Polymer Engineering and Science, Vol. 43, No. 2, 490-500.

5. M. Garcia, G. van Vliet, S. Jain, B. A. G. Schrauwen, A. Sarkissov, W.E. van Zy and B. Boukamp, (2004). Polypropylene/SiO 2 nanocomposites with improved mechanical properties, Reviews on Advanced Materials Science 6, 169-175.

6. A.A.Cuadri, J.E.Martin Alfonso, (July 2017). The effect of thermal and thermo-oxidative degradation conditions on rheological, chemical and thermal properties of HDPE, Polymer Degradation and Stability, Volume 141, Pages 11-18.

7. D.P.Serrano, J. Aguado, G. Vicente,N. Sanchez, (January 2007).Effects of hydrogen-donating solvents on the thermal degradation of HDPE, Journal of Analytical and Applied Pyrolysis, Volume 78, Issue 1, Pages 194-199.

8. D.G.Dikobe, A.S.Luyt, (August 2017).Thermal and mechanical properties of PP/HDPE/wood powder and MAPP/HDPE/wood powder polymer blend composites, Thermochimica Acta, Volume 654,, Pages 40-50.

9. Ifigenia Grigoriadou, Eleni Pavlidou, Kostas M, (July 2018). Paraskevopoulos, ZoiTerzopoulou, Dimitrios N, Bikiaris, Comparative study of the photochemical stability of HDPE/Ag composites, Polymer Degradation and Stability, Volume 153, Pages 23-36.

10. Gavali, V. C., Kubade, P. R., \& Kulkarni, H. B. Mechanical And Thermomechanical Properties Of Carbon Fibre Reinforced Thermoplastic Composite Fabricated Using Fused Deposition Modelling (Fdm) Method: A Review.

11. Regina Jeziorska, Agnieszka, Szadkowska, Maria Zielecka, Magdalena, Wenda, Blanka Kepska,( November 2017). Morphology and thermal properties of HDPE nanocomposites: Effect of spherical silica surface modification and compatibilizer, Polymer Degradation and Stability, Volume 145, Pages 70-78.

12. K.Chrissafis, K.M.Paraskevopoulos,E.Pavlidou,D.Bikiaris, (March 2009).Thermal degradation mechanism of HDPE nanocomposites containing fumed silica nanoparticles, Thermochimica Acta,Volume 485, Issues 1-2, Pages 65-71.

13. Pingan Song, Zhengping Fang, Lie Shen, Mao Peng, ( July 2010). Thermal degradation and flammability properties of HDPE/EVA/ C60 nanocomposites, Hui Liu, Thermochimica Acta,Volume 506, Issues 1-2, Pages 98-101.

14. ShuangqiaoYang, Shibing Bai, Qi Wang,( November 2016). Morphology, mechanical and thermal oxidative aging properties of HDPE composites reinforced by nonmetals recycled from waste printed circuit boards, Waste Management, Volume57, Pages 168-175.

15. Rongzhi Li,(2000) Environmental degradation of wood-HDPE composite,, Polymer Degradation and Stability, Volume 70, Issue 2, Pages 135-145.

16. L.Minkova, Y.Peneva, E.Tashev, S.Filippi, M.Pracella, P.Magagnini,(August 2009). Thermal properties and microhardness of HDPE/clay nanocomposites compatibilized by different functionalized polyethylenes, Polymer Testing, Volume 28, Issue 5, Pages 528-53. 
17. M. Rjeb, A. Labzour, A. Rjeb, S. Sayouri, Y. Claire, A. Perichaud, (2005). TG and DSC studies of naturaland artificial aging of polypropylene, Physica A 358, 212-217.

18. G. Gutierrez, F. Fayolle, G. Regnier, J. Medina, (2010). Thermal oxidation of clay-nanoreinforced polypropylene, Polymer Degradation and Stability 95, 1708-1715.

19. Yu Hua Ge, Jing Yi Kang, Jun-Hong Zhou, Liang-Wei Shi, (2016). Theoretical investigation on thermal aging mechanism and the aging effect on mechanical properties of HTPB-IPDI polyurethane, Computational Materials Science 115 92-98.

20. Florencio G. Ramos Filho, Tomas Jeferson A. Melo, Marcelo S. Rabello, Suedina M.L. Silva, (2005).Thermal stability of nanocomposites based on polypropylene and bentonite, Polymer Degradation and Stability 89,383-392.

21. H. Ravisankar, Pydi Hariprasadarao V. Chittaranjan Das, G Bhanukiran, (2018). "Effect of nanoclay inclusion on mechanical and fatigue behavior of ABS/PP/HDPE thermoplastics", International Conference on "Advances in Materials and Manufacturing Applications (IConAMMA 2018)" during 16 $6^{\text {th }}-18^{\text {th }}$ Aug 2018. 
